\section{Case Reports in Neurology}

\title{
Acute Ischemic Stroke in a Young Patient with Left Ventricular Thrombus Attributed to Doxorubicin Cardiomyopathy
}

\author{
Eung-Joon Lee Byung-Woo Yoon \\ Department of Neurology, Seoul National University Hospital, Seoul, Republic of Korea
}

\section{Keywords}

Stroke $\cdot$ Young adults $\cdot$ Brain infarction $\cdot$ Cardiomyopathy $\cdot$ Doxorubicin

\begin{abstract}
We report a case of acute middle cerebral territory ischemic infarction caused by left ventricular thrombus (LVT) in a doxorubicin cardiomyopathy patient. A major adverse effect of doxorubicin is cardiotoxicity. In doxorubicin cardiomyopathy, as the ventricular contractility decreases, LVT can occur and lead to systemic embolic events such as stroke.

(C) 2020 The Author(s)

Published by S. Karger AG, Basel
\end{abstract}

\section{Introduction}

Left ventricular thrombus (LVT) is one of the serious complications of ischemic heart disease [1]. It is also identified in patients with other nonischemic cardiomyopathies. The incidence of LVT in patients with nonischemic cardiomyopathies is 11-44\% [2-4]. LVT can cause left ventricular systolic dysfunction and lead to thromboembolic complications such as stroke. Doxorubicin, an anthracycline antibiotic commonly used as a chemotherapeutic agent, is known to cause cardiotoxicity. The morphologic and functional derangements of doxorubicin cardiomyopathy are similar to those of dilated cardiomyopathy [5]. Blood stasis due to ventricular dysfunction can cause formation of thrombi. In this report, we describe the case of a

$\begin{array}{ll} & \text { Byung-Woo Yoon } \\ \text { Department of Neurology, Seoul National University Hospital } & 101 \text { Daehak-ro, Jongno-gu } \\ & \text { Seoul 03080 (Republic of Korea) } \\ \text { bwyoon@snu.ac.kr }\end{array}$




\section{Case Reports in Neurology}

Case Rep Neurol 2020;12:178-182

DOI: $10.1159 / 000502414$

(c) 2020 The Author(s). Published by S. Karger AG, Basel www.karger.com/crn

Lee and Yoon: Acute Ischemic Stroke in a Young Patient with LVT

patient with doxorubicin cardiomyopathy who experienced left middle cerebral artery (MCA) territory infarction caused by left ventricular thrombi.

\section{Case Report}

A 38-year-old woman was referred to our institution with aggravated dyspnea and leftsided chest pain associated with profuse sweating and restlessness. She had a history of osteosarcoma at the right distal femur diagnosed at age 13. It was successfully treated with a combination of surgery and chemotherapy with doxorubicin. However, 3 months after the completion of four cycles of chemotherapy, the patient complained of dyspnea and chest pain which gradually became worse. Cardiomyopathy was diagnosed at age 14 because ventricular dysfunction was confirmed in echocardiography. Ejection fraction was $17 \%$ at the time. Since then she has been taking propranolol.

At the time of admission, her general, physical, and systemic examination was unremarkable. Electrocardiography was suggestive of anteroseptal wall myocardial infarction. Her serum creatine kinase-muscle/brain (CK-MB) level was $18.8 \mathrm{ng} / \mathrm{mL}$ (reference: 0-6.6 ng/mL) and her troponin-I level was $5.84 \mathrm{ng} / \mathrm{mL}$ (reference: $0-0.028 \mathrm{ng} / \mathrm{mL}$ ). The rest of the hematological investigations were within normal limits. Transthoracic echocardiography revealed global hypokinesia with severely depressed systolic function. Calculated left ventricular ejection fraction was $21 \%$. There was a large LVT $(2 \times 0.61 \mathrm{~cm})$ at the apex (Fig. 1a). However, her coronary angiography showed no evidence of coronary artery disease. Therefore, anticoagulation was initiated promptly with a low-molecular-weight heparin (LMWH). Subcutaneous enoxaparin at a dose of $1 \mathrm{mg} / \mathrm{kg}$ was given twice daily. The patient's heart symptoms gradually improved. CK-MB and troponin I levels normalized after 4 days of anticoagulation.

Prior to discharge, the patient wanted tooth extraction from the dentist. LMWH was discontinued for 1 day in consultation with the dentist. She had no symptoms until she started to sleep that day, however, when she woke up the next morning, she presented global aphasia and weakness of her right arm and leg. Her initial National Institutes of Health stroke scale score was 19. In her initial evaluation, electrocardiography revealed sinus rhythm. Brain magnetic resonance (MR) imaging confirmed an acute infarct in the left MCA territory (Fig. 2a, b). MR angiography indicated a left proximal MCA occlusion (M1 segment) (Fig. 2c). Perfusion MR imaging of time-to-peak map showed that the delayed perfusion area was much larger than the lesion in the diffusion-weighted imaging (Fig. 2d). There was MR imaging-based perfusion-diffusion mismatch, and it was judged that there was salvageable tissue. Therefore, mechanical thrombectomy was performed by using the Solitaire stent system. Successful recanalization of the left MCA was achieved. The patient was transferred to the stroke care unit. On next day, brain computed tomography showed no hemorrhagic transformation. Therefore, LMWH administration was restarted immediately and was changed to warfarin and maintained (target international normalized ratio: 2.5 ). Rehabilitation continued and weakness of the right upper and lower extremities and her language function gradually improved. She was discharged after 1 month. Oral warfarin was maintained and adjusted according to international normalized ratio values. A repeat echocardiogram was performed at the follow-up visit 3 months after discharge. It showed complete resolution of the LVT (Fig. 1b). At 3 months the modified Rankin scale score was 1 and she had recovered to walk alone. Although fluency was scarce, there was no big problem in language understanding. The patient was stable and no evidence of embolism was seen after the treatment.

\section{Karger'=}




\section{Case Reports in Neurology}

Lee and Yoon: Acute Ischemic Stroke in a Young Patient with LVT

\section{Discussion and Conclusion}

In our case there were no other factors that could have caused the stroke, yet LVT was detected. We conclude that this patient had cerebral infarction due to LVT associated with doxorubicin cardiomyopathy. To the best of our knowledge, this is the first report of stroke at a young age attributed to LVT caused by doxorubicin cardiomyopathy. Previously, stroke due to doxorubicin-induced cardiac toxicity was reported, but this is the first time LVT has been identified by echocardiography [6]. In addition, our case has significance in that ischemic infarction occurs late in adulthood after doxorubicin treatment in childhood.

LVT is commonly known as a serious complication of myocardial infarction. However, it is also present in patients with nonischemic cardiomyopathies. Our patient had developed LVT probably due to ventricular dysfunction caused by doxorubicin cardiomyopathy. She was diagnosed with osteosarcoma at age 13 and treated by chemotherapy including doxorubicin. Doxorubicin is well known for its cardiotoxicity. Doxorubicin cardiotoxicity can be acute, occurring during and within 2-3 days of its administration. The mechanisms for these acute changes are not clear but probably due to doxorubicin-induced myocardial edema, which is reversible. However, the toxicity of doxorubicin can be chronic. Symptoms usually develop late in the course of therapy, but may occur years later. The incidence of doxorubicin cardiomyopathy is primarily related to doxorubicin dose. The incidence is about $4 \%$ when the dose of doxorubicin is $500-550 \mathrm{mg} / \mathrm{m}^{2}, 18 \%$ when the dose is $551-600 \mathrm{mg} / \mathrm{m}^{2}$, and $36 \%$ when the dose exceeds $600 \mathrm{mg} / \mathrm{m}^{2}$ [7]. Other risk factors are combination treatment with other cardiotoxic drugs and mediastinal radiation therapy. Doxorubicin therapy in childhood and adolescence predisposes to the occurrence of doxorubicin cardiomyopathy in adults [8]. Age is also a risk factor; there is a high likelihood of cardiotoxicity when the patient is very young or very old.

Multiple mechanisms are proposed for doxorubicin-induced cardiotoxicity [9]. Doxorubicin-induced cardiomyopathy is associated with an increase in oxidative stress. Myofibrillar loss and intracellular calcium dysregulation are also important. Doxorubicin cardiomyopathy is commonly manifested as chronic dilated cardiomyopathy. The ventricular ejection fraction and contractile function is reduced. LVT may occur with left ventricular dysfunction and can lead to systemic embolic events. Once LVT is diagnosed, anticoagulation should be started immediately [10].

Our patient continued to take warfarin for 2 years and there was no more embolic event. The thrombus was no longer observed on follow-up echocardiography. It is important to remember that cardiomyopathy may occur during the treatment or later in patients who received doxorubicin in childhood, which could be a cause of stroke in young adults.

\section{Statement of Ethics}

Written informed consent for publication of her case (including publication of images) was obtained from the patient.

\section{Conflict of Interest Statement}

The authors have no conflicts of interest to declare.

\section{Karger'=}




\section{Case Reports in Neurology}

\begin{tabular}{l|l}
\hline Case Rep Neurol 2020;12:178-182 \\
\hline DOI: 10.1159/000502414 & $\begin{array}{l}\text { @ 2020 The Author(s). Published by S. Karger AG, Basel } \\
\text { www.karger.com/crn }\end{array}$ \\
\hline
\end{tabular}

Lee and Yoon: Acute Ischemic Stroke in a Young Patient with LVT

\section{Funding Sources}

The authors received no financial support for the research, authorship, or publication of this article.

\section{References}

1 Nixon JV. Left ventricular mural thrombus. Arch Intern Med. 1983 Aug;143(8):1567-71.

2 Wilensky RL, Jung SC. Thromboembolism in patients with decreased left ventricular function: incidence, risk, and treatment. J Cardiovasc Risk. 1995 Apr;2(2):91-6.

3 Mir JU, Raheel Jahangir J, Asfandyar Q, Sher Ali K, Syed Abbas A, Muhammad Zeeshan H. Left ventricular thrombus in patients with acute anterior wall myocardial infarction. J Ayub Med Coll Abbottabad. 2014 Oct-Dec;26(4):491-5.

4 Bakalli A, Georgievska-Ismail L, Koçinaj D, Musliu N, Krasniqi A, Pllana E. Prevalence of left chamber cardiac thrombi in patients with dilated left ventricle at sinus rhythm: the role of transesophageal echocardiography. J Clin Ultrasound. 2013 Jan;41(1):38-45.

5 Chatterjee K, Zhang J, Honbo N, Karliner JS. Doxorubicin cardiomyopathy. Cardiology. 2010;115(2):155-62.

6 Kara G, Taşoğlu O, Dizdar O, Altundağ K, Ozçakar L. Stroke due to doxorubicin-induced cardiac toxicity. Med Oncol. 2009 Dec;26(4):506-7.

7 Lefrak EA, Pitha J, Rosenheim S, Gottlieb JA. A clinicopathologic analysis of adriamycin cardiotoxicity. Cancer. 1973 Aug;32(2):302-14.

8 Broder H, Gottlieb RA, Lepor NE. Chemotherapy and cardiotoxicity. Rev Cardiovasc Med. 2008;9(2):75-83.

9 Octavia Y, Tocchetti CG, Gabrielson KL, Janssens S, Crijns HJ, Moens AL. Doxorubicin-induced cardiomyopathy: from molecular mechanisms to therapeutic strategies. J Mol Cell Cardiol. 2012 Jun;52(6):1213-25.

10 Ebrahimi M, Fazlinezhad A, Alvandi-Azari M, Abdar Esfahani M. Long-term clinical outcomes of the left ventricular thrombus in patients with ST elevation anterior myocardial infarction. ARYA Atheroscler. 2015 Jan;11(1):1-4.
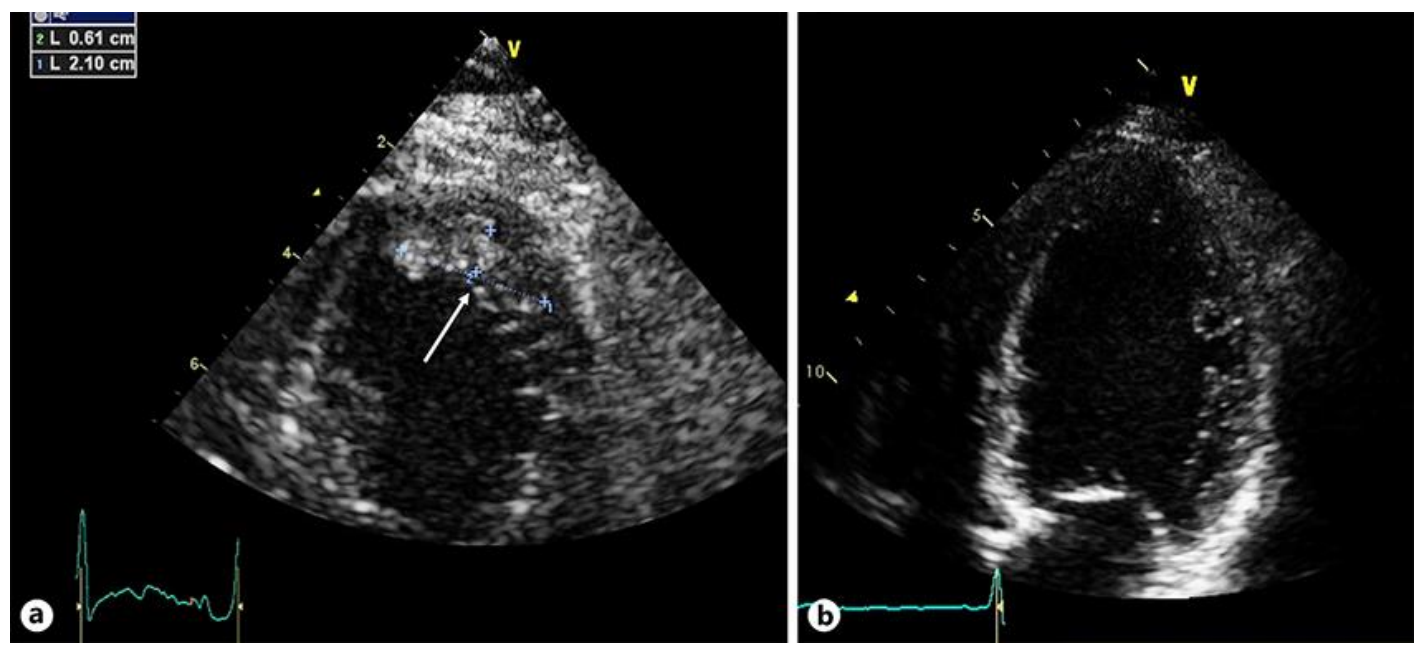

Fig. 1. a Transthoracic echocardiography showed a large $(2 \times 0.61 \mathrm{~cm})$ left ventricular thrombus at apex (arrow). b After 3 months of anticoagulation therapy, follow-up echocardiography revealed that the thrombus was resolved. 
Case Reports in Neurology

\begin{tabular}{l|l}
\hline Case Rep Neurol 2020;12:178-182 \\
\hline DOI: 10.1159/000502414 & $\begin{array}{l}\text { @ 2020 The Author(s). Published by S. Karger AG, Basel } \\
\text { www.karger.com/crn }\end{array}$ \\
\hline
\end{tabular}

Lee and Yoon: Acute Ischemic Stroke in a Young Patient with LVT
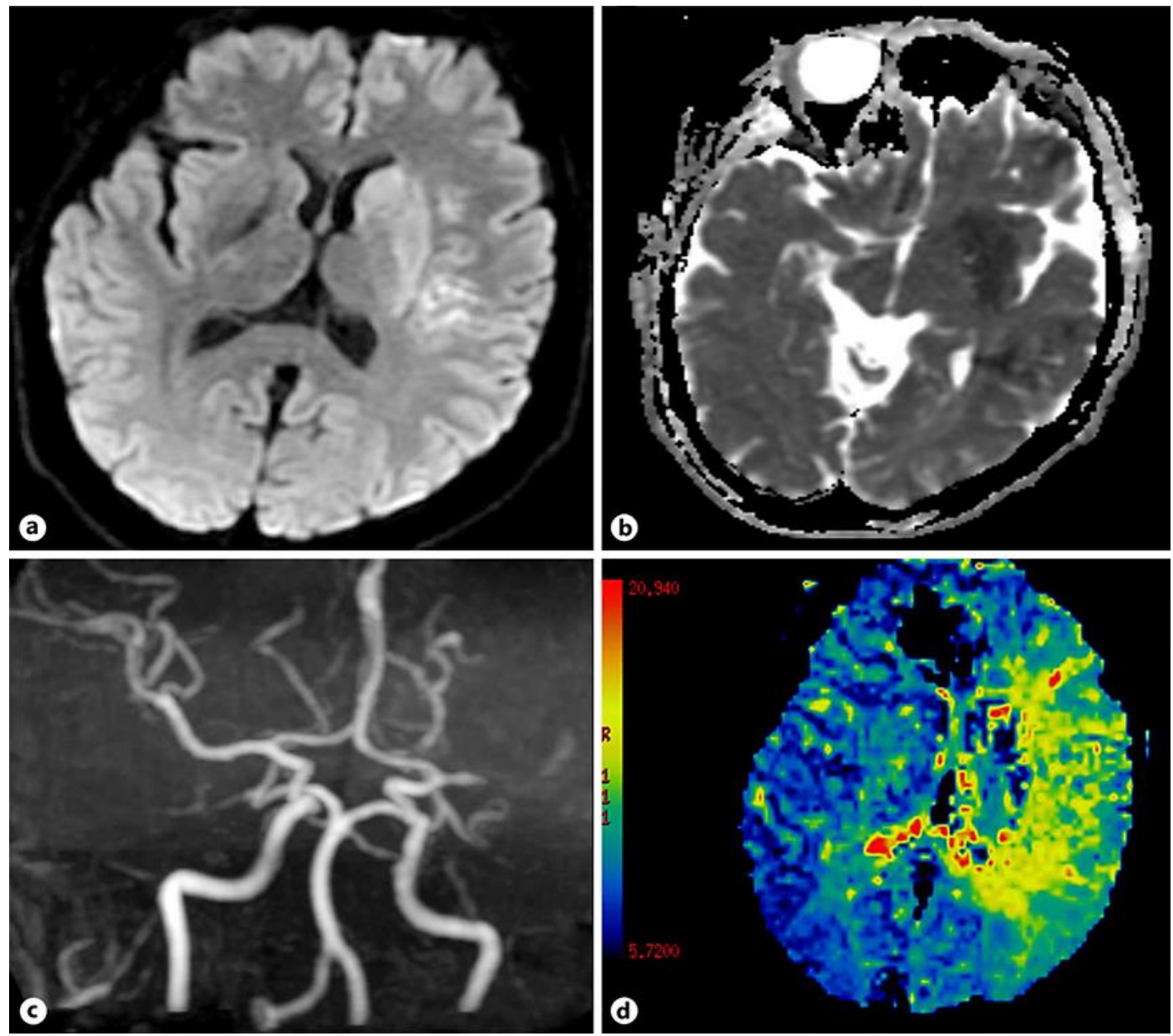

Fig. 2. a, b Brain MR imaging showed left MCA territory infarction. c MR angiography showed left proximal MCA occlusion. $\mathbf{d}$ Perfusion MR image of time-to-peak map showed delayed perfusion of the left MCA territory. MCA, middle cerebral artery; MR, magnetic resonance. 